\title{
ASYMPTOMATIC UNILATERAL OVARIAN LEIOMYOMA IN A GERMAN SHEPHERD BITCH
}

\author{
Alessandro Pecile, Debora Groppetti, Valeria Grieco, Gabriele Barella, \\ Melania Moioli, Stefano Faverzani \\ Department of Veterinary Medicine, Faculty of Veterinary Medicine, \\ Università degli Studi di Milano, via G. Celoria 10 - 20133 Milano, Italy
}

Received 20 May 2016; Received in revised form 19 September 2016; Accepted 2 October 2016

\begin{abstract}
This report shows for the first time clinical imaging (ultrasound and computed tomography), histological and immunohistochemical findings of an ovarian leiomyoma, coincidentally diagnosed in an asymptomatic unmated nulliparous ten year-old German shepherd bitch concurrently suffering from multiple mammary tumors. A thorough examination allowed the differentiation of ovarian leiomyoma from other spindle cell tumors. An accurate description of the diagnostic procedures useful in the managing of ovarian leiomyoma could provide valuable information to veterinary practitioners. Indeed, despite its rarity and nonspecific symptoms, ovarian leiomyoma may also affect the dog with an unknown potential risk.
\end{abstract}

Key words: dog, ovary, leiomyoma, diagnosis

\section{INTRODUCTION}

Ovarian leiomyoma is a very rare benign tumor mainly occurring in women around their menopause period, but also observed in young and pregnant patients, and often associated with uterine leiomyoma $(1,2)$. In dogs, leiomyomas commonly involve the vulva, vagina and uterus (3) while they represent only $2 \%$ of the ovarian tumors whose incidence ranges from $0.5 \%$ to $6 \%$ (4). The cause of canine reproductive tumors is unknown, but ovarian hormones are thought to play a strong role (5). Leiomyomas have been reported in association with chronic oestrogen stimulation mainly in dogs also affected by cystic endometrial hyperplasia and mammary gland tumors, which are known to result

\footnotetext{
Corresponding author: Dr. Debora Groppetti, $\mathrm{PhD}$

E-mail address: debora.groppetti@unimi.it

Present address: Università degli Studi di Milano

Faculty of Veterinary Medicine

Department of Veterinary Medicine,

via G. Celoria 10 - 20133 Milano, Italy

Phone: +39-02-503-18151

Fax: $+39-02-503-18148$

Copyright: (C) 2016 Pecile A. This is an open-access article published under the terms of the Creative Commons Attribution License which permits unrestricted use, distribution, and reproduction in any medium, provided the original author and source are credited.

Competing Interests: The authors have declared that no competing

interests exist.

Available Online First: 4 November 2016

Published on: 15 March 2017

http://dx.doi.org/10.1515/macvetrev-2016-0093
}

from hormonal influence (5). Leiomyomas are slow growing, non-invasive, non-metastatic, smooth muscle masses (5) and are mostly discovered incidentally either during abdominal examination, at surgery or at necropsy, both in humans and animals (6). In symptomatic women, the presentations can vary from either abdominal pain, mass per abdomen, hydronephrosis or polymiositis (6).

To date, few documented cases of ovarian leiomyoma have been reported in dogs. There is a lack of knowledge about the clinical impact of this rare tumor. Therefore, the present study offers a descriptive diagnostic procedure with a broad term follow up of a patient suffering from ovarian leiomyoma and providing food for speculative thought about its prognostic expectation.

\section{CASE HISTORY AND DIAGNOSTIC PROCEDURES}

An unmated nulliparous ten year-old German shepherd bitch, weighing $36.6 \mathrm{~kg}$, was presented with a history of multiple mammary gland masses. The owner reported a regular reproductive cycle (approximately every 6 months), the last one occurring about 2 months before, and repeated pseudopregnacies. No hormonal treatment for 
prevention or suppression of the heat, neither abortifacient drugs had ever been administered. On physical examination, the bitch appeared healthy with no disease other than mammary gland masses. In addition, haematological and biochemical parameters were all within normal values. Ovarian anomalies were coincidently diagnosed during routine pre-surgical investigations. Abdominal ultrasound examination performed with a twodimensional and Doppler tool (Esaote MyLab 70, Genua, Italy) equipped with a 4-8 $\mathrm{MHz}$ microconvex and a 7.5-13 $\mathrm{MHz}$ linear transducer to stage the mammary tumors, disclosed that both ovaries increased in volume with a polycystic aspect. The right ovary had heterogeneous echogenicity due to multiple thin-walled anechoic structures. Moreover, a patchy hypoechoic lesion measuring up to $70 \mathrm{~mm}$ in diameter with irregular outer contours was detected (Fig. 1 a). The left ovary was $50 \mathrm{~mm}$ in size and, as the right ovary, showed cystic with many fluid-filled structures measuring up to $20 \mathrm{~mm}$, sometimes confluent, and with distal enhancement (Fig. 1 b). The uterus and other abdominal organs seemed normal.

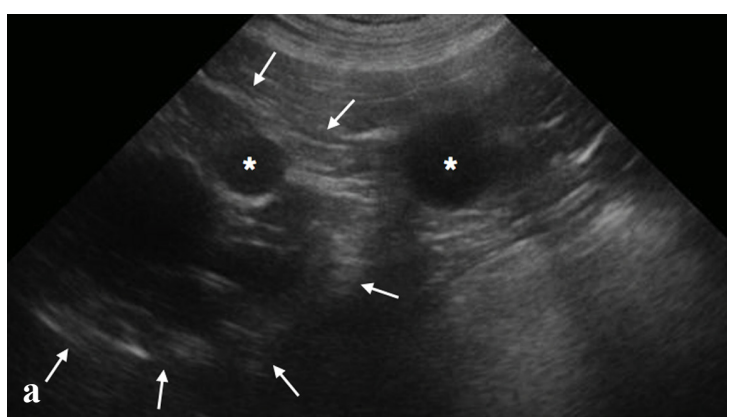

Figure 1. Sonographic appearance of the ovary. Right ovary: anechoic structures (*) and hypoechoic mass (arrows) (a). Left ovary: anechoic structures (*) (b)

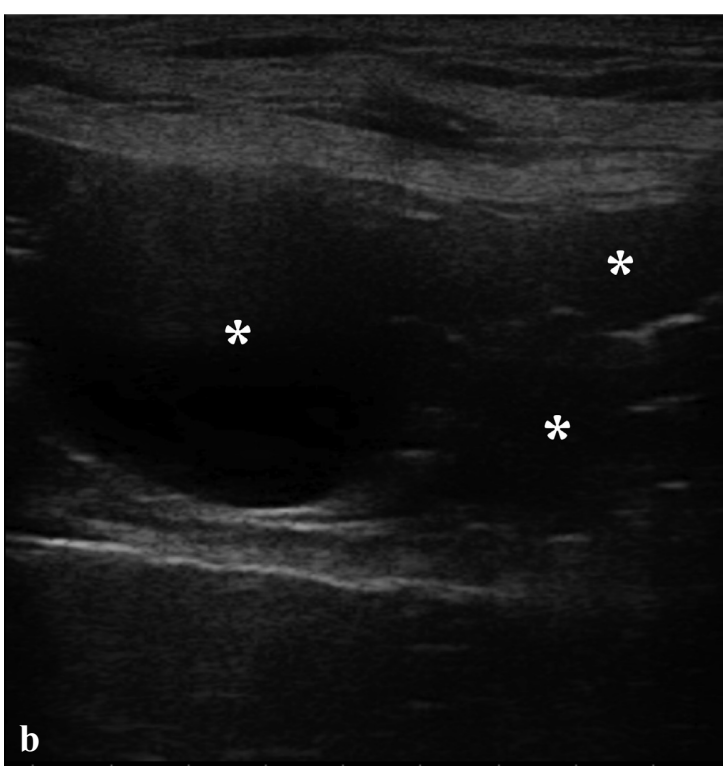

b

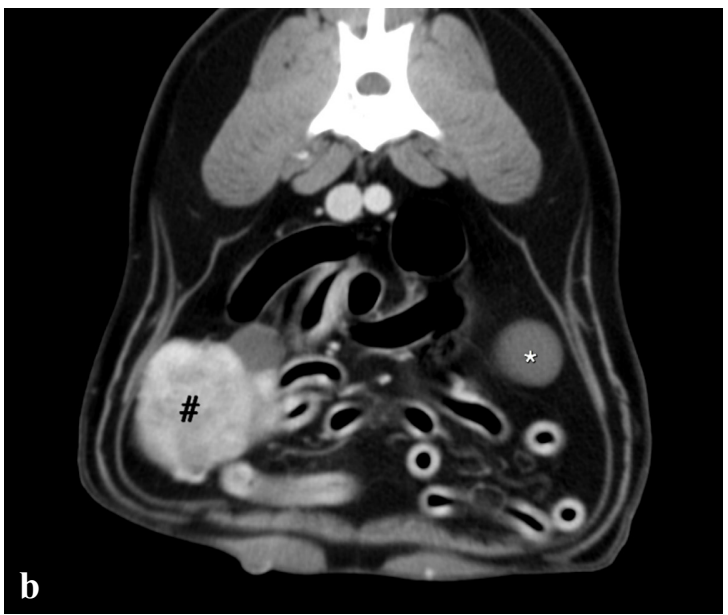

Figure 2. Post-contrast CT scan. Cystic aspect of both ovaries (right ovary *; left ovary $\S$ ) (a). A more caudal scan showing the right (\#) and the left (*) ovary (b). 
The dog underwent a pre- and post-contrast computed tomography (fourth-generation single-slice scanner mod. PQ2000S, Philips MS, Eindhoven, Holland) study of thorax and abdomen that confirmed a bilateral increase of the ovarian volume (right ovary 32 x 37 x 69 mm; left ovary 53 x 48 x 92 mm). After i.v. administration of $600 \mathrm{mgI} / \mathrm{kg}$ Omnipaque ${ }^{\mathrm{TM}} 350(\mathrm{GE}$ Healthcare AS, Oslo, Norway) contrast medium, both ovaries showed a severe and heterogeneous uptake sharpening, rounded hypodense areas with irregular and thin hyperdense margins (Fig. 2 a). This aspect was suggestive of a cystic nature. In the right ovary (Fig. 2 b \#), a solid highly vascularized component (45 x 51 x $40 \mathrm{~mm}$ ) showing heterogeneous and severe contrast uptake was evident and suggestive of a large space-occupying lesion. In the left ovary (Fig. $2 \mathrm{~b} *$ ), hypodense cystic areas coexisted with an irregularly shaped area expressive of normal luteal ovarian tissue.

After performing ovariohysterectomy in a routine manner (7), we proceeded with a total unilateral mastectomy for the removal of mammary tumors (8). At surgery both ovaries were surrounded by the ovarian bursae and were enlarged in size with extensive cystic degeneration (Fig. 3 a). The uterus appeared normal. On dissection, the right ovary showed that it completely changed into a solid whitish mass with a shiny smooth outer surface and firm consistency (Fig. $3 \mathrm{~b})$. The cut surface of the mass displayed a whorled pattern. Grossly, there was no recognizable normal ovarian tissue (Fig. 3 c). Parovarian cysts were also detected (Fig. 3 c). The left ovary showed a luteal appearance and many parovarian cysts were also detected (Fig. 3 b, c). The surgically removed tissues were then submitted for pathological examination.
After fixation in 10\% neutral buffered formalin and embedding in paraffin wax, $5 \mu \mathrm{m}$ thick sections were obtained from all surgically removed tissues and stained with haematoxylin and eosin (HE) for histological examination. Immunohistochemical staining was performed as in previous report (9) on deparaffinized sections of the ovarian neoplastic mass with the avidin-biotin-peroxidase complex (ABC; Vector Laboratories, Burlingame, CA) technique (10).

Histology identified the mass at the right ovary level as a tumor, composed by interlacing bundles of spindle cells characterized by a moderate amount of eosinophilic cytoplasm and elongated basophilic nuclei. Neoplastic cells showed minimal cellular atypia and low mitotic activity ( $<1 \mathrm{HPF})$. Necrosis was absent. The left ovary showed corpora lutea without any pathological feature. Bilateral parovarian cysts were thin walled structures lined by a simple cuboidal epithelium. A slight cystic endometrial hyperplasia was recorded.

Due to gross and histological similarities between ovarian leiomyoma and other spindle cell tumors such as thecoma and fibroma, an appropriate immunohistochemical test was performed to allow differential diagnosis (2). Immunohistochemical staining showed neoplastic cells as positive for desmin and $\alpha$-smooth muscle actin (Fig. 4 a,b). These results, together with the histological appearance, confirmed the diagnosis of ovarian leiomyoma.
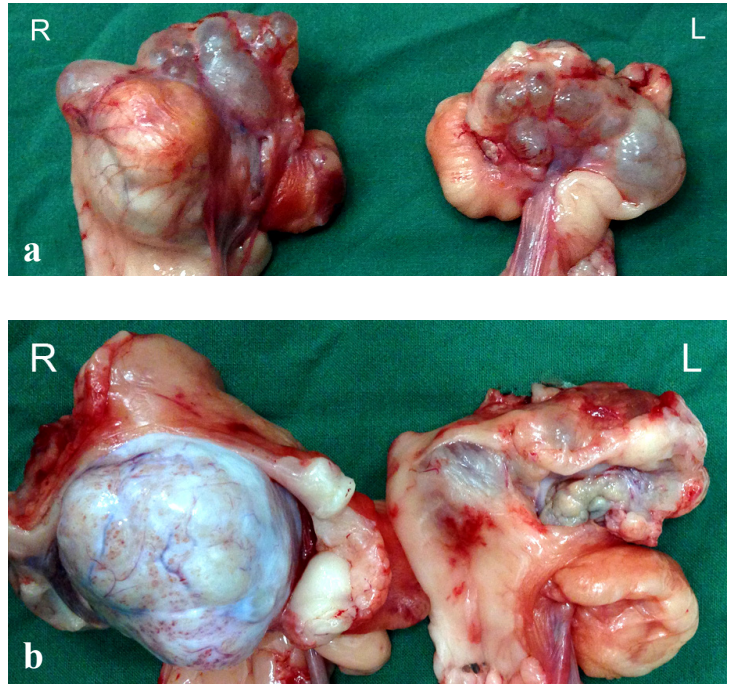

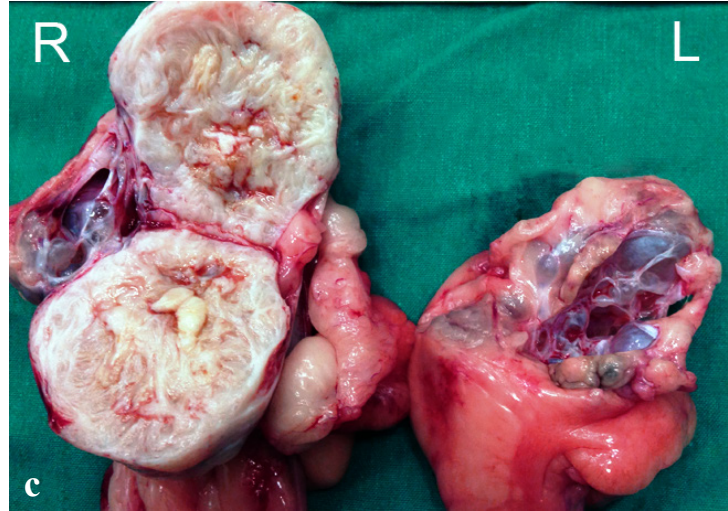

Figure 3. Macroscopic aspect of the ovaries. Right (R) and left (L) ovary still enclosed within the bursae (a), after dissection of the bursae (b), and after incision (c). 

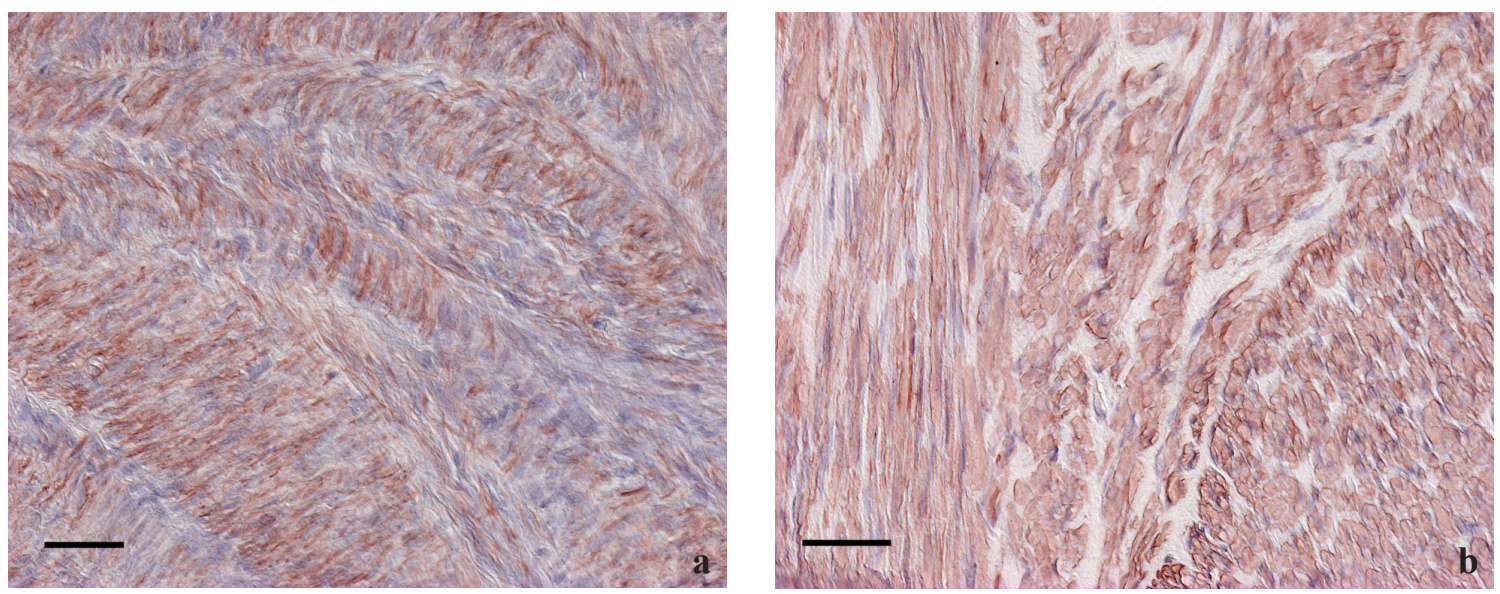

Figure 4. Immunohistochemical aspect of the neoplastic mass in the right ovary. The cytoplasm of neoplastic cells was strongly stained for the anti-desmin monoclonal antibody (a) and the anti- $\alpha$-actin (smooth muscle) monoclonal antibody (b). Avidin-biotin peroxidase complex (ABC). Bar $=100 \mu \mathrm{m}$.

Multiple findings from hyperplasia to papilloma and adenocarcinoma were observed in the whole mammary chain. Inguinal lymph nodes showed a mild follicular hyperplasia.

About one year after surgery, a splenectomy was necessary for removal of a low grade myxoid liposarcoma. Six months later the dog was euthanized due to the onset of pulmonary metastases.

\section{DISCUSSION}

The histogenesis of ovarian leiomyoma is uncertain. This tumor could arise from smooth muscle cells of the ovarian hilar blood vessels walls, but other possible origins include cells in the ovarian ligament, smooth muscle cells or multipotential cells in the ovarian stroma, undifferentiated germ cells, or cortical smooth muscle metaplasia $(6,11)$. Ovarian leiomyomas are considered as benign tumors, including those which are 'mitotically active', and are treated conservatively (12). However, no definitive criteria to distinguish between benign and malignant smooth-muscle tumors of the ovary have been established in human and the criteria used for uterine smooth-muscle tumors have usually been applied (2).

Ovarian leiomyoma often co-exists with uterine leiomyoma and has been recently reported together with an ovarian myxoid liposarcoma in a dog (13), suggesting a common aetiology or identical hormonal stimulation (6). In the present case, either cystic endometrial hyperplasia, mammary gland tumors, ovarian leiomyoma and splenic liposarcoma, were diagnosed in a ten year-old German shepherd bitch who died as a result of lung metastases.

Clinic, ultrasonographic, computed tomography, histological and immunohistochemical aspects of the ovarian leiomyoma described in this study were similar to the human counterpart (12). Indeed, ovarian leiomyoma was characterized by a well-circumscribed soft tissue mass with an internal swirling pattern and variable echogenicity (determined by extent of degeneration and fibrosis) (1). The tomographic aspect was consistent with ovarian leiomyoma described in humans as a heterogeneous mass with severe contrast enhancement (14).

\section{CONCLUSION}

This report highlights an extremely unusual entity describing its clinical and diagnostic aspects, and the associated neoplastic events throughout a lifetime follow-up. The expansion of shared case studies can contribute to a deeper knowledge of this rare disease in dogs, which is essential to diagnose and manage ovarian leiomyoma that, however, may occur in clinical practice with an unknown potential risk.

\section{CONFLICT OF INTEREST STATEMENT}

The authors declared that they have no potential conflict of interest with respect to the authorship and/or publication of this article. 


\section{REFERENCES}

1. Lalwani, N., Shanbhogue, A.K., Bhargava, P., Vikram, R., Prasad, S.R. (2012). Rare, miscellaneous primary ovarian neoplasms: spectrum of crosssectional imaging. Current Problems in Diagnostic Radiology 41, 73-80.

http://dx.doi.org/10.1067/j.cpradiol.2011.07.026 PMid:22285004

2. Murakami, M., Uehara, H., Nishimura, M., Iwasa, T., Ikawa, H. (2010). A huge ovarian smooth muscle tumor: a case report. The Journal of Medical Investigation 57, 158-162.

http://dx.doi.org/10.2152/jmi.57.158

PMid: 20299756

3. MacLachlan, N.J., Kennedy, P.C. (2002). Tumors of the genital systems. In: Meuten D.J. (Ed.), Tumors in domestic ani $\neg$ mals IV (pp 547-574). Iowa USA: Iowa State University Press. http://dx.doi.org/10.1002/9780470376928.ch11

4. Sforna, M., Brachelente, C., Lepri, E., Mechelli, L. (2003). Canine ovarian tumors: a retrospective study of 49 cases. Vet Res Commun. 27 Suppl. 1, 359-366. http://dx.doi.org/10.1023/B:VERC.0000014180.77684.52

5. Sathya, S., Linn, K. (2014). Regression of a vaginal leiomyoma after ovariohysterectomy in a dog: a case report. J Am Anim Hosp Assoc. 50, 424-428. http://dx.doi.org/10.5326/JAAHA-MS-6082 PMid:25251430

6. Gunasekaran, I., Phansalkar, M., Palo, L.B., Varghese, R.G. (2015). Ovarian leiomyoma along with uterine leiomyomata: a common tumor at an uncommon site. Journal of Clinical and Diagnostic Research 9, ED01-ED02.

http://dx.doi.org/10.7860/JCDR/2015/13378.6703

PMid:26674537 PMCid:PMC4668420

7. Howe, L.M. (2006). Surgical methods of contraception and sterilization. Theriogenology 66, 500-509.

http://dx.doi.org/10.1016/j.theriogenology.2006.04.005 PMid:16716381
8. Rutteman, G.R., Withrow, S.J., Macewen, E.G. (2001). Tumors of the mammary gland. In J. Withrow, E.G. MacEwen (Eds.), Small Animal Clinical Oncology (pp. 538-556). St. Louis USA: Elsevier Sanders.

9. Grieco, V., Locatelli, C., Riccardi, E., Brambilla, P. (2008). A case of two different tumors in the heart of a dog. J Vet Diagn Invest. 20, 365-368.

http://dx.doi.org/10.1177/104063870802000320 PMid:18460629

10. Hsu, S.M., Raine, L., Fanger, H. (1981). Use of avidin-biotin-peroxidase complex (ABC) in immunoperoxidase techniques: A comparison between $\mathrm{ABC}$ and unlabeled antibody (PAP) procedures. J Histochem Cytochem. 29, 577-580. http://dx.doi.org/10.1177/29.4.6166661 PMid:6166661

11. Wei, C., Lilic, N., Shorter, N., Garrow, E. (2008). Primary ovarian leiomyoma: a rare cause of ovarian tumor in adolescence. J Pediatr Adolesc Gynecol. 21, 33-6.

http://dx.doi.org/10.1016/j.jpag.2007.07.001

PMid:18312799

12. Lewill, M.F., Sung, R., Oliva, E., Prat, J., Young, R.H. (2004). Smooth muscle tumors of the ovary: a clinicopathologic study of 54 cases emphasizing prognostic criteria, histologic variants, and differential diagnosis. Am J Surg Pathol. 28, 1436-1451.

http://dx.doi.org/10.1097/01.pas.0000141393.99300.d0 PMid: 15489647

13. Shiwa, N., Boonsriroj, H., Kimitsuki, K., Shimatsu, T., Park, C.H. (2016). The co-existence of a myxoid liposarcoma and leiomyoma in the same ovarian mass of a dog. J Vet Med Sci 78(3): 467-471.

http://dx.doi.org/10.1292/jvms.15-0467 PMid:26522811 PMCid:PMC4829519

14. Mathew, M., Gonsalves, H., Al-Azawi, S., Saparamadu, P.A. (2013). Asymptomatic ovarian mucinous cystadenoma with a solid mural leiomyoma: Case report and brief review. Sultan Qaboos Univ Med J. 13, 127-131. http://dx.doi.org/10.12816/0003206 PMid:23573393 PMCid:PMC3616778 